\title{
The Design Co-ordination Framework: key elements for effective product development
}

\author{
M M Andreasen \\ Dept. of Control and Engineering Design, \\ Technical University of Denmark, DK-2800 Lyngby, DK. \\ A H B Duffy and K J MacCallum \\ CAD Centre, University of Strathclyde, 75 Montrose Street, \\ Glasgow G1 1XJ, UK. \\ J Bowen \\ Dept. of Computer Science, UCC, College Road, Cork, Ireland \\ T Storm \\ Laboratory of Flexible Production Automation, \\ Delft University of Technology, Delft, NL
}

\begin{abstract}
This paper proposes a Design Co-ordination Framework (DCF) i.e. a concept for an ideal DC system with the abilities to support co-ordination of various complex aspects of product development. A set of frames, modelling key elements of coordination, which reflect the states of design, plans, organisation, allocations, tasks etc. during the design process, has been identified. Each frame is explained and the co-ordination, i.e. the management of the links between these frames, is presented, based upon characteristic DC situations in industry. It is concluded that while the DCF provides a basis for our research efforts into enhancing the product development process there is still considerable work and development required before it can adequately reflect and support Design Co-ordination.
\end{abstract}

\section{Introduction}

Competitive advantage can be achieved by a number of different means [1]. Within the current market environment, enterprises are being required to become increasingly responsive to changing and diverse customer needs, while being able to introduce and deliver their products more efficiently and at competitive prices. That is, manufacturing enterprises need to ensure:

- shorter time to market,

- improved quality and customer satisfaction, and

- competitive costs.

Over the past decade industrialists and academics have recognised the need and importance of developing approaches to enhance competitive advantage within 
manufacturing companies [2-14]. For example approaches such as: Enterprise Modelling which focuses upon the effective utilisation of the material use and manufacturing process within a company's business environment and the total integration of the enterprise $[15,16]$; and Concurrent Engineering (CE) which has been primarily directed at ways of performing tasks in parallel and has resulted in a number of methods being developed as suggested by Vasilash [17], such as simultaneous engineering, life cycle engineering, process driven design, team approach, and design for manufacture.

In particular, the significance of the design process in determining the success or failure of a product in the market place and hence influencing a company's market strength is becoming increasingly more articulated $[1,18-20]$. It is becoming more apparent that there is considerable scope for substantial improvements and efficiency gains within design. A survey carried out in the mid-80s suggested that overall 'effectiveness' of development engineering is around 4\% [21]. The basis for this statistic is that, on average, engineers reported spending around one third of their time doing "real" design, of this only one third was spent solving the "right" problems, and of this management have the right competencies for only one third of the time (i.e. $1 / 3 \times 1 / 3 \times 1 / 3 \approx 4 \%$ ). That is, a considerable amount of time and effort is wasted by the lack of focus on the application and management of design effort. This leads to the conclusion that the potential for improvement in better productive use of engineering design resources is substantial - provided we have the mechanisms to realise it.

Unfortunately Enterprise Modelling approaches do not directly address the issues prevalent within Product Design Development and hence do not provide a means or foundation upon which to optimise the design process. These approaches have tended to concentrate upon global company functioning, strategy, overall business development and have tended to be directed at providing a high level director/managers' tool. Thus a major weakness of these approaches is that they do not directly address the issues involved in the actual design activity of complex and multi-disciplinary design projects.

An indication of the complexity of formalising the design process comes from the large number of descriptions which exist in the literature and which attempt to represent the essence of design [22]. What is interesting about these descriptions is their variety as well as the fact that they emphasise different aspects, according to the interpretation or findings of the author(s). They have also tended to model design as a chain of activities and have not taken into account the many complexities [23], life phase aspects [24] and business/enterprise issues [25] which are essential considerations for conducting effective design. Consequently, in recent years we have seen a trend which moves away from these "traditional" models towards "Concurrent Engineering".

CE research represents considerable global effort to shorten the design cycle time, improve the design quality, or reduce product costs. Within Western Europe the emphasis has been upon approaches which consider the product's life cycle issues 
[26-29] and the total integration of the market, design, and production functions of a business [30]. Thus, European work has tended to concentrate upon shortening the design cycle time by introducing and addressing life cycle issues earlier in the design process in order to alleviate problems and define a better quality of product by way of an integrated development process. In the United States of America (USA), more emphasis has been placed upon co-operative working as typified by the DICE (DARPA Initiative in Concurrent Engineering) program [8, 31] workshops [32], books such as that entitled 'Computer-Aided Co-operative Product Development' [33], and research publications [34-37]. In addition, supporting information sharing [38, 39] and design management [40-45] are currently topical issues in American CE research. While the research effort in Europe has tended to concentrate upon life cycle issues, the USA emphasis has primarily been upon enhancing integration and communications of human and computer resources. However the ethos in both continents has been one of attempting to follow the CE philosophy.

The design of complex products involves the co-ordinated organisation of multidisciplinary groups, activities and information which continually evolve and change during the design process. Historically, different activities in the design process have been kept separate and interact through informal and formal communications, via paper medium or file transfers, resulting in considerable effort going into the resolution of inconsistencies, conflicts, and uncoordinated design activities. The design process is becoming increasingly and inextricably linked to computational design tools and data models which invariably remain disparate. Before multi-design tasks can be effectively organised and co-ordinated within such a computer medium, there is a need to integrate the data of the product model and the design tools in order to make effective use of the resources available. Such an environment can provide not only a basis upon which to develop multi-disciplinary design and dynamic project team organisations but also consistent, co-ordinated and efficient product development.

A major shortcoming of the Concurrent Engineering view is the failure to recognise that what is truly required is not for activities to be carried out in parallel but for resources to be effectively utilised in order to carry out tasks for the right reasons, at the right time, to meet the right requirements and give the right results. That is:

the key to achieving optimal design performance, and hence design productivity, is the effective co-ordination of the design process.

The authors of this paper have been involved in a working group of researchers (CIMDEV) which was funded by the Commission of the European Communities ESPRIT initiative from September 1992-1995, and subsequently as the Integration in Manufacturing and Beyond (IIMB) group from September 1996-1999. The group was initially formed in order to foster and develop collaborative links in basic research for DEVices (i.e. software tools) for Computer Integrated 
Manufacture (CIM). Since its inception, a sub-group of CIMDEV has played a leading role in the development of a key issue in design research - Design Coordination (DC) - which has now been adopted by the wider European group as a unifying concept for several areas of research, each examining different aspects of this central theme [46].

The argument for Design Co-ordination (DC) is that, to optimise design, activities should not necessarily be carried out "concurrently" but should be structured in such a fashion as to achieve optimum performance (such as total life quality and costs, cycle times, profitability, etc.). To achieve this, Design Co-ordination focuses upon issues directly relevant to the optimisation of the design process. Thus, the DC sub-group has formulated the following mission for the project:

- to achieve a quantum leap in the performance of the Product Development Process.

With the principal goal:

- to develop a computer based environment which supports the effective utilisation and integration of resources in order to optimise the design process.

This paper presents a framework for the effective co-ordination of the product design development process, the Design Co-ordination Framework (DCF). It is based upon the cumulative experience of the authors working in the field and discussions with a number of leading manufacturing companies. It is a hypothesis of the key elements involved in Design Co-ordination and as such forms the basis for discussion and a foundation to focus our research activities. Within the paper, before describing the DCF, a general outline of Design Co-ordination is given. Mechanisms for Design Co-ordination are then presented and the use of the framework in design discussed. The paper concludes the DCF it requires more thorough validation and will no doubt be subject to change and evolution.

\section{Design Co-ordination}

Design co-ordination may be seen as the activity of covering the need for coordinating the design activity in itself due to its own complexity, and the need for co-ordinating within complexities of activities, resources, goals and tasks of the company.

Design may be viewed as human and creative problem solving and engineering activities, market and commercial activities of product development, and planning and strategy related management activities of product planning. Co-ordination should bring these activities into a total organisational and commercial context [47]. 
The complexities which design co-ordination should cope with have been identified in an earlier publication [48]: the complexity of the artefact, the design activity, decision making, actors, aspects, knowledge and sources. Design Coordination brings these parameters together and allows for the management and control of the Co-ordination. One pattern of co-ordination is today well known and has high effects: concurrent product development. Concurrency is obtained by coordinating in accordance with creation of simultaneity, integration and providence of the activities of designing [48].

Establishing an interactive Design Co-ordination system means to manipulate important design factors like tasks, resources and design aspects related to the time dimension of designing. Design Co-ordination may therefore be seen as four main activities: decision making, controlling, modelling and planning/scheduling, with respect to the mentioned factors, see Table 1 [48].

\begin{tabular}{|l|c|c|c|c|}
\hline Activities & $\begin{array}{c}\text { Decision } \\
\text { making }\end{array}$ & Controlling & Modelling & $\begin{array}{c}\text { Planning/ } \\
\text { Scheduling }\end{array}$ \\
\hline Time & & & & $\sqrt{ }$ \\
\hline Aspects & & $\sqrt{ }$ & \\
\hline Resources & & $\sqrt{ }$ & & \\
\hline Tasks & $\sqrt{ }$ & & & \\
\hline
\end{tabular}

Table 1. Activities of design co-ordination related to design factors [48].

The complexities of the design activity mentioned above are dimensions or parameters, which change state and structure during the design activity. The artefact to be designed grows in complexity, gradually new resources are brought in, new tasks are planned and a long row of different models support the synthesis, analysis and documentation activities. Decision making plays a central role, relating the organisation members with more or less influence on the artefact and the activities.

\section{Key Elements - A Set Of Frames For Design Co-ordination}

If we want to show or monitor the design activity and keep track of all the important relations between the activity and the company, what key elements do 
we need? In this section we try to identify this set of frames, where a frame is a model, showing the change of state or the change of relations.

Figure 1 shows a proposal for a set of frames for product development. The frames reflect the authors and a number of industrialists believe to be the most important aspects, but make no claim on completeness or correctness.

Each frame represents a particular aspect of design co-ordination, their state, evolution and relations. They represent models of different aspects of design. These models are not as yet matured in research or practise, because their role has been mind-setting or explanatory rather than as explicit tools. Thus, some of the models are new and find little support in the literature.

\subsection{Model of Product Development - Frame 1}

Product development is the activity which links need recognition to the introduction to the market place. There exists many theoretical, normative models in the literature (Eekels \& Rozenberg [49], Pahl \& Beitz [50], Hollins \& Pugh [51], Andreasen \& Hein [30] and many more) and many companies use templates or master procedures for their design activity (e.g. Lucas [52], Philips [53], Stork [54]). The models are given many names, which adds to confusion: Total Design [55], Product Introduction Process (PIP) [52], Integrated Product Development $[30,56]$, Product Life Cycle [57].

The content of such models differs widely, from simple problem solving models, via engineering design focused models, to models showing interrelated functional activities of a company, leading to establishing a new business.

The nature of the models differ from theoretical (principal) and generic models, procedural models (fitted to the company's normal standard activity, defining standard sub-activities and their sequences and relations), master plans (with detailed planning schemes, but not fitted to the actual project) and actual plans on different levels of scope and detail, i.e. showing the project strategy, the tactics or the operational activity pattern.

Such models or procedures may be related to a company handbook or manual, explaining each activity (input, output, definition, responsibility, methods, tools etc.). The handbook may be structured in accordance with the companies quality handbook, ISO 9000, or similar regulations. 


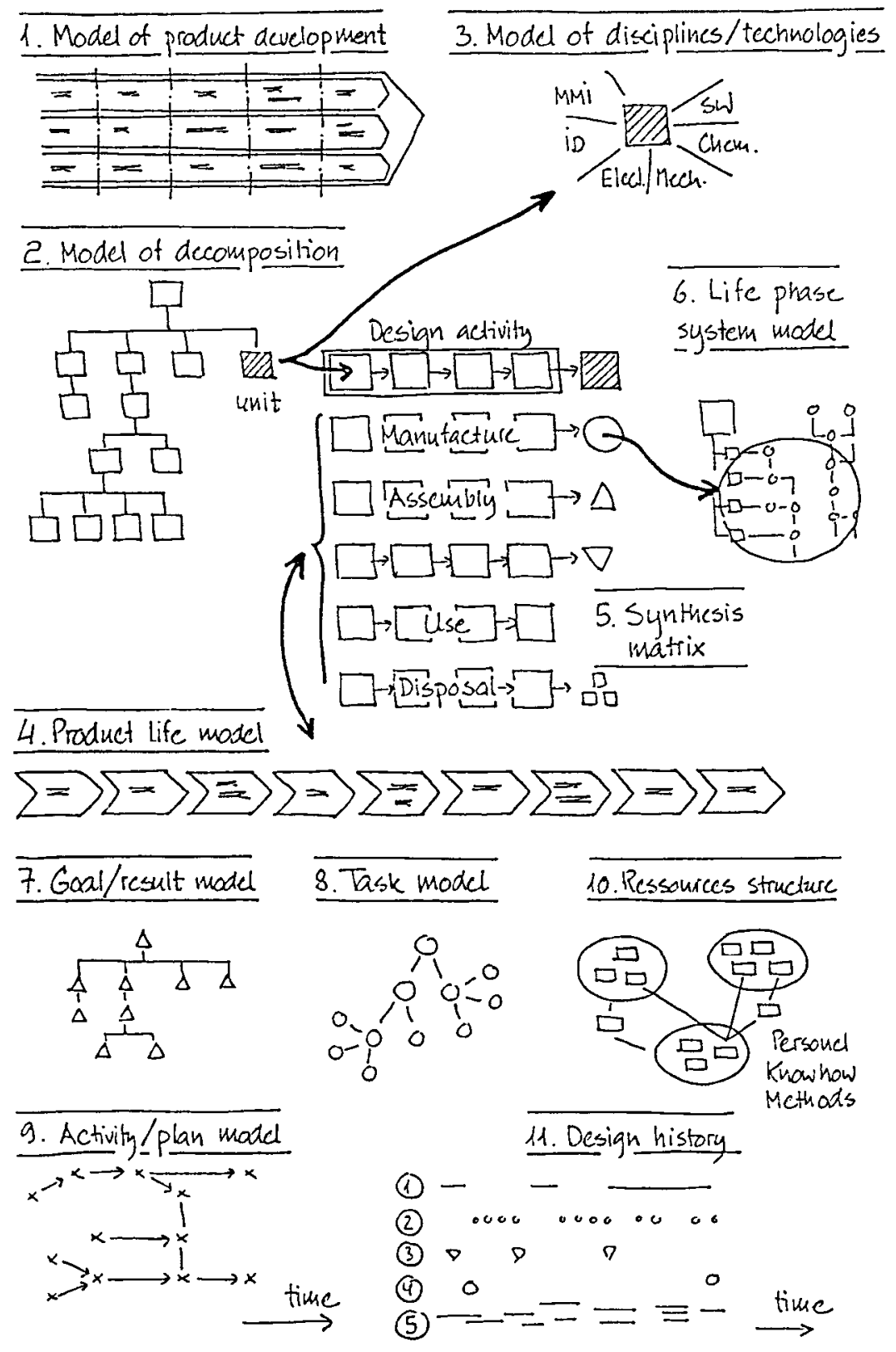

Figure 1: Set of frames for design co-ordination. Each frame symbolises a monitoring model. Co-ordination means establishing, managing, and controlling proper dynamic relations and inter-action between these frames. 
The DC support related to this model could be:

- support of planning

- use of generic activity decomposition patterns

- reuse of plan patterns from earlier projects

- communication of the plan to different involved partners

The frame would show the activity elements, milestones, patterns of activities, relations, critical path, actors or agents involvement and event related links from one activity to others. The time dimension and the scheduling is treated below when discussing Frame 9.

\subsection{Model of decomposition - Frame 2}

Decomposition is the product breakdown into (functionally defined) subsystems, each of which constitutes a design activity. There exist other types of design activities, which cannot be precisely related to subsystems, so the decomposition model is not a full activity structure model.

Pragmatic, experience based decomposition is made in many companies, as a basis for activity planning and parallel design, performed by different individuals or teams. Here there are only immature theories in literature [58], plus mathematical, optimisation oriented decomposition styles [59, 60], which are not applicable for general practise.

The entities of the decomposition may be identified and modelled in different ways: as functional black-boxes, as structured elements with functional or spatial relations, or as part structures with assembly relations [61].

As the design activity is progressing, new subsystems are identified in a mainly hierarchical manner, and each subsystem is transformed from functional identification, via conceptual design, into a detailed part structure (Frame 5).

Such a model could be required to provide:

- a definition and overview of product subsystems

- an overview of alternative design routes and alternative solutions to subsystems

- an overview of reuse areas of the product (known subsystems)

- an overview of design progress of each subsystem.

The frame is a hierarchical structure of units, where each unit represents a subsystem by its identity, degree of classification, and where you have the possibility to see an illustration (e.g. CAD drawing) of each subsystem, when requested. 


\subsection{Model of disciplines and technologies - Frame 3}

Product development changes technologies and know-how into new business possibilities. The R\&D organisation has to gain new insights and ideas for use in the design activity. The $\mathrm{R} \& \mathrm{D}$ organisation have to be multidisciplinary in accordance with the needs of the product for creating mechanical, electronic or software solutions or to create a control circuit, a man/machine interface, optimisation of a fluid flow system etc.

It is necessary to divide the tasks of the design activity in accordance with the disciplines, but also to integrate those disciplines in such a way as to achieve overall optimal solutions. Seen from the manager of the design department it is necessary to create continuous and professional development of each discipline while the design projects need a limited professional contribution, e.g. for solving a software problem related to some logic of the man/machine interface.

At present we see the discipline model as a "discipline content and distribution" model of the artefact to be designed, but also the disciplines and expertise required to develop the design. It is recognised however that this model needs considerably further clarification and development

\subsection{Product life model - Frame 4}

Designing is closely linked to foreseeing product life phases, primarily the "use" phases, but also establishment, maintenance and liquidation. The perception of these phases or the product life scenario may be rather concrete and sure, due to familiarity of existing products, or unsure and unknown. But in any case the designer's task is to fit the product to an imagined life scenario.

Each life phase may be seen as a system; the product interacts with this system and the effectiveness of that interaction determines the performance and ease of performing/surviving the actual phase. Such life phase systems could be production, sales, transport, service or recycling systems [24]. The product specification normally defines the range and focus of life concerns and raises the need for a product life model for monitoring this range and focus and the need for relating product life facts to the design activity.

The functionality related to a product life model could be to:

- support for defining or identifying product life range and focus

- support for reuse of product life scenario and data from familiar, earlier products, established on the market place

- overview of design progress related to product life concern

- monitoring of product life aspects like cost, quality and environmental effects. 
The monitoring of this frame could be supported by symbolic life phase/life cycle models, related data views or focusing on selected life aspects like total life costs $[62,63]$.

\subsection{Synthesis Matrix model - Frame 5}

The synthesis of the artefact is the core of the product development activity. Each subsystem or larger parts of the product may be treated in a separate design activity. The design activity may be unstructured or captured in steps with defined phase results like, for example, a concept. The literature and industrial practise offer many different models of the design activity, more or less fitted to product types and the type of industry, see Frame 1.

Adopting the concept of Concurrent Engineering we propose a parallel product and production engineering process $[30,53,64]$. The phases are synchronised and performed interactively and there are two results: a product and a production result. The content of the production engineering activity may range from a fully developed production system (e.g. a new automated assembly cell) to a quantitative fitting (selection of tools, jigs and production flow pattern) of the production system to the product.

Expanding this idea to other product life phases reveals a similar concept of parallel synthesis. The range of life phases should be in accordance with the range and focus of the product life model, see Frame 4. The output of each activity is a definition of the life phase conditions and/or systems. Thus, not only should issues involved in DFX be considered but also the X element but must also be designed and evolved along with the product. That is, we must Design The X (DTX) in order to ensure the overall business and product requirements are met.

The use of the synthesis matrix, i.e. the realisation of concurrent synthesis, could be the following:

- support for planning

- support for reuse of plan patterns

- support for reuse of concurrency patterns

- monitoring of parallel design progress

- communication of the plan and progress to relevant participants (e.g. partners or sub-contractors), showing updates and changes.

The frame representing the synthesis matrix could be a symbolic diagram or a principal activity relation network, with links to the results or to intermediate phase results and links between such results.

\subsection{Life phase system model - Frame 6}

As mentioned above, the concurrent system, identification or quantification of a life phase system has as a result a contribution to the specification of the life phase system and the life phase conditions. The responsible agents for the life phase (like 
the fabrication, assembly, transport or service department) need to receive these explicit results for control, adjustment or as a specification for the future life phase activity, like input for production preparation.

The need related to life phase system modelling is to model the different contributions from the synthesis activities and to transfer these contributions to the actual agent in their professional language. An example could be the transfer of chosen assembly methods, sequences, gripper surface information etc. to the assembly department, for contribution to the production preparation and the establishment of the assembly system.

For example, the assembly department may use this model to:

- obtain insight to assembly related design results

- control the development of the life phase system

- evaluate consequences on considerations such as cost and lead time

- allow reaction (feedback) to the design activity

- allow further detailing and progression in production planning.

The number of agents "receiving" this type of monitoring should be in accordance with the main focus of the design activity, mirrored in the product life model, see Frame 4. Some agents are not departmental, like installation and recycling, and in these cases the frame would serve the purposes of the design team.

The frame could reflect the assembly sequence contributions for each synthesised unit and the system layout contribution. Many life cycle areas have not developed characteristic models which again is an area requiring further consideration and development.

\subsection{Product development goal/result model - Frame 7}

The product development activity is normally controlled by goal specifications. The specifications define demands and optimisation criteria and specific required elements or features of the solution, with the basic idea to capture the properties of the ideal solution covering the perceived need.

Ideally seen this overall specification should be broken down into subsystem specifications as the design activity progresses, allowing evaluation and selection of best solutions for the subsystem. This breakdown should also ensure that subsystems in a proper way contribute to the overall optimisation of the total system.

State of the art of this area is not in accordance with this ideal situation. In some branches of industry specifications are not used. In more developed companies you find the breakdown of specifications only for sub-supplier deliveries or for choice of materials or units like motors, gears etc. The QFD method (Quality Function Deployment [65]) requires the breakdown of technical specifications from the total 
system via components to production processes and control operations, but no theoretical basis exists. The existence of a goal structure is foreseen by Ropohl [66] and some theoretical steps have been made [58].

As the design activity is progressing, the specifications are met and results may be formulated, i.e. a solution specification may be formulated. This specification reflects the decomposition model, and as the design progresses in detail, the results sum-up to overall performance parameters of the system [58].

The goal structure relates to a degree the decomposition structure. The specification elements (demands) cannot be related to the system elements beforehand, unless the solution is already well known. So the relation between the specification and the system elements is normally very complicated.

The aspects of DC that this model could provide support for are to:

- monitor the gradual elaboration of sub-specifications

- monitor the satisfaction of specifications and the obtained system performance

- control the results of the design activity at its milestones

- allow dynamic adjustments and additions.

The goal/result model is an overview of the specification elements and their relations to the decomposition structure. Each element within the goal structure could reflect a full specification document and also show the obtained resulting values.

\subsection{Product development task model - Frame 8}

The tasks of the team manager and the product development team may be formulated in a business specification which defines the purpose and goal of a project seen from a business point of view and act as a contract between the management and the team.

Also individuals and functional units of the basic organisation has formulated tasks to fulfil. Due to the nature of product development, where each new product changes the conditions for all functional units, these units also have specific tasks which are required to be performed in order to develop the product. Tasks of this nature could be cost reduction, service rationalisation, reduction of order treatment lead time, creation of data links to $\mathrm{R} \& \mathrm{D}$, internal standardisation, ISO 9000 certification etc.

The defined tasks are more or less directly related to the product development activity and the solutions may be complicated: When do I, as service manager, interfere with the design activity for obtaining higher quality of the service departments activities? 
Monitoring the task structure is complicated, but rewarding. There exist no theory or practise, but we believe that the transparency created by a Design Co-ordination system could allow the relations between the tasks and the product development activities to be explicitly expressed. In this way important links between product development and the basic organisation is established and may be managed.

\subsection{Activity model - Frame 9}

As outlined in Frame 1, many companies use a general master model of the product development activity as a basis for establishing a plan for an actual project. Where the model of the product development activity mentioned in Frame 1 serves the overview and monitoring of a set of activities (mainly showing strategy and tactics plus milestone actions), the activity model serves the control of teams and individual activities.

The DC support of an activity model could be the following:

- support the creation and maintenance of the project plan under dynamic changes

- support the reuse of plans from earlier projects

- communication of a common plan to all teams and agents involved in the project.

\subsection{Resource model - Frame 10}

An important task in design management is the allocation of resources. What are allocated are knowledge, skills and methods, carried by individuals, teams and equipment.

There are no models of the resources structure in current use in practise. The resources do not follow a hierarchy, they more likely reflect a network structure, where some of the nodes are agents outside the borders of the company.

The support from the resource model could be:

- identification and overview of resources and their network

- support for resource allocation and the utilisation of earlier resource allocations (experiences), related to the manager

- current and planned loading and allocations

- support for resource contributions seen from the agents point of view.

We consider that there is considerable effort and development required to adequately model the available resources, and support their effective utilisation, within the Design Co-ordination Framework (DCF).

\subsection{Design history model - Frame 11}

A design history model reflects central aspects of the product development activity, such as decisions and their rationale, related to product oriented solutions, 
design strategies, plans, allocations etc. The use of such a design history could be to:

- support documentation related to ISO 9000 etc.

- support reuse or any kind of insight obtained by previous projects

- allow learning from previous projects.

The design history model of the DCF is not in fact an active monitoring element, but more a passive register, with the ability to replay and reuse particular aspects of past design experience in order to optimise the co-ordination activity.

\section{Mechanisms Of Design Co-ordination}

In the previous section we proposed a set of frames, or monitoring models. We consider that the frames in themselves are important contributions for monitoring the design activity. In the following we will identify, how Design Co-ordination is related to these eleven frames. The frames themselves do not reflect co-ordination, but rather the elements involved in its support. Co-ordination relates to the effective control and management of the inter-relations between these frames, through appropriate DC mechanisms.

The need for co-ordination is related to the many complexities involved in design and the dynamic changes of design management parameters. Identifying the mechanisms of Design Co-ordination is partly a theoretical task, for setting up principal mechanisms, and a practise oriented task, finding those mechanisms which are important for an actual company in an actual situation.

A theoretical analysis could be an investigation of relations between frames created by dynamic changes in the design activity. We could ask for example: Where do we find the Design Co-ordination activity "decision making" in these dynamic patterns? In Design Co-ordination decisions are made, concerning artefacts, as part of synthesis and, about paths or "navigation" within the design activity. You find decision making on many levels, creating a continuum from strategic decisions down to detailed decisions of the designer. Therefore we find no strict demarcation of DC decision making.

Clarifying the decision making activities may be done in a matrix of the eleven frames, where it is noted, how a change in one frame could lead to decisions related to the same or other frames, see Figure 2. The result is a complex pattern, even if we only note higher level management oriented decisions, and the analysis does not tell us anything about the importance of the decisions and the need for coordination support 


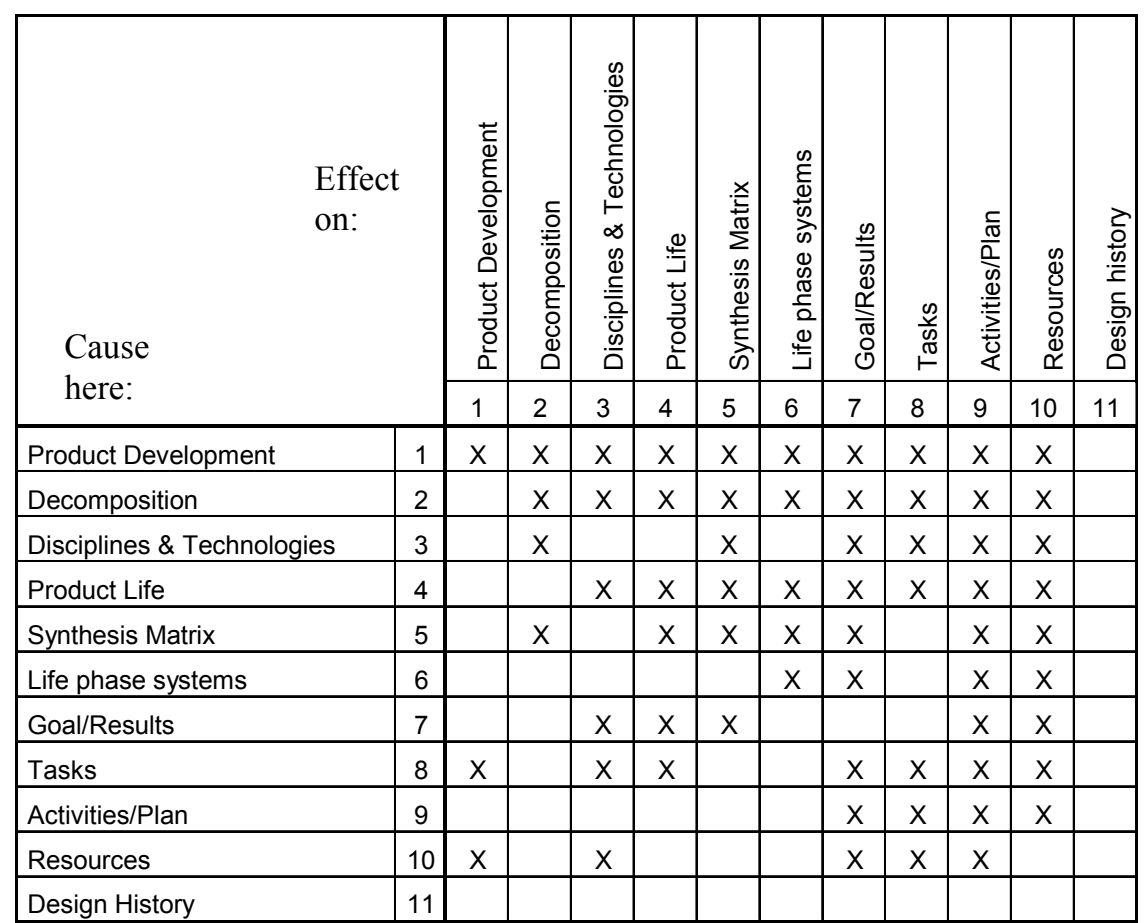

Figure 2: Design co-ordination occurs when changes in one frame (vertical list) propagate decisions about change in another frame (horizontal list). The crosses mark the principal decision related links.

Another approach, also theoretical, would be to set up a semantic net of dynamic changes. An example is shown in Figure 3, where two frames are related, namely the "Model of decomposition" and the "Synthesis matrix" with focus on a unit being designed. This analysis is very general and does not lead to a detailed definition for development in say a computer based system.

In Figure 4 is shown a similar analysis linking the "Model of decomposition", "Goal structure" and "Activity model" based on the identification of a new unit in the decomposition structure. 


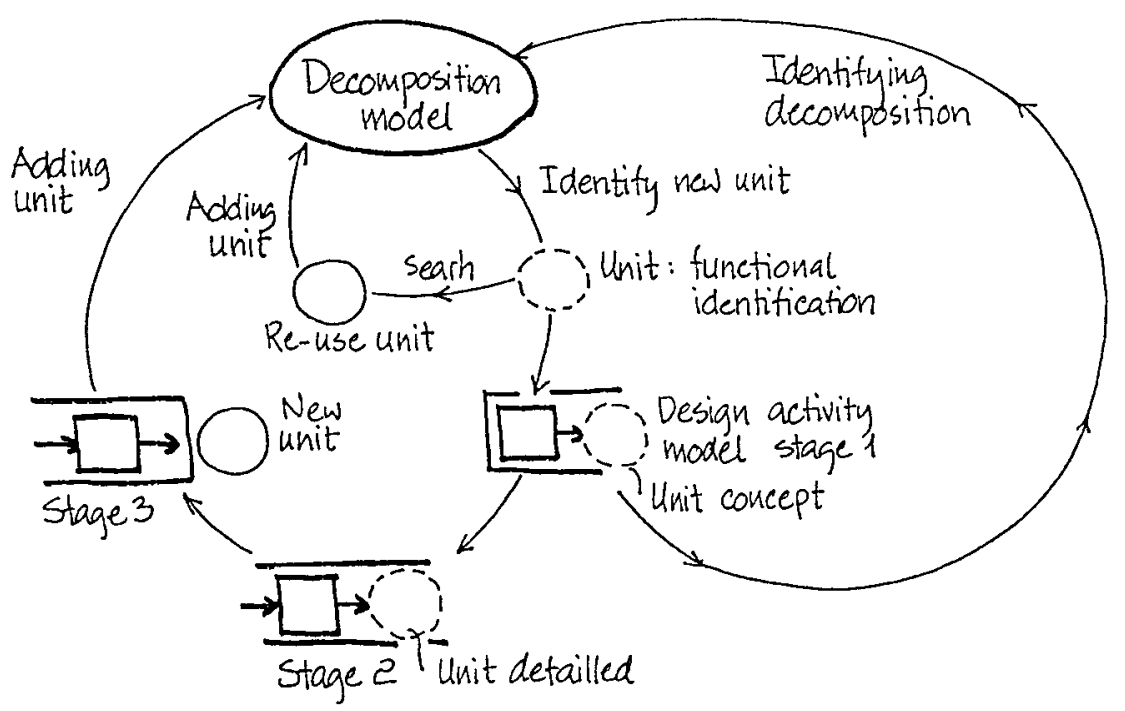

Figure 3 Example of analysis of dynamic changes in the frame network. Here two frames are related, namely the model of decomposition and the synthesis matrix model, with focus on the unit design.

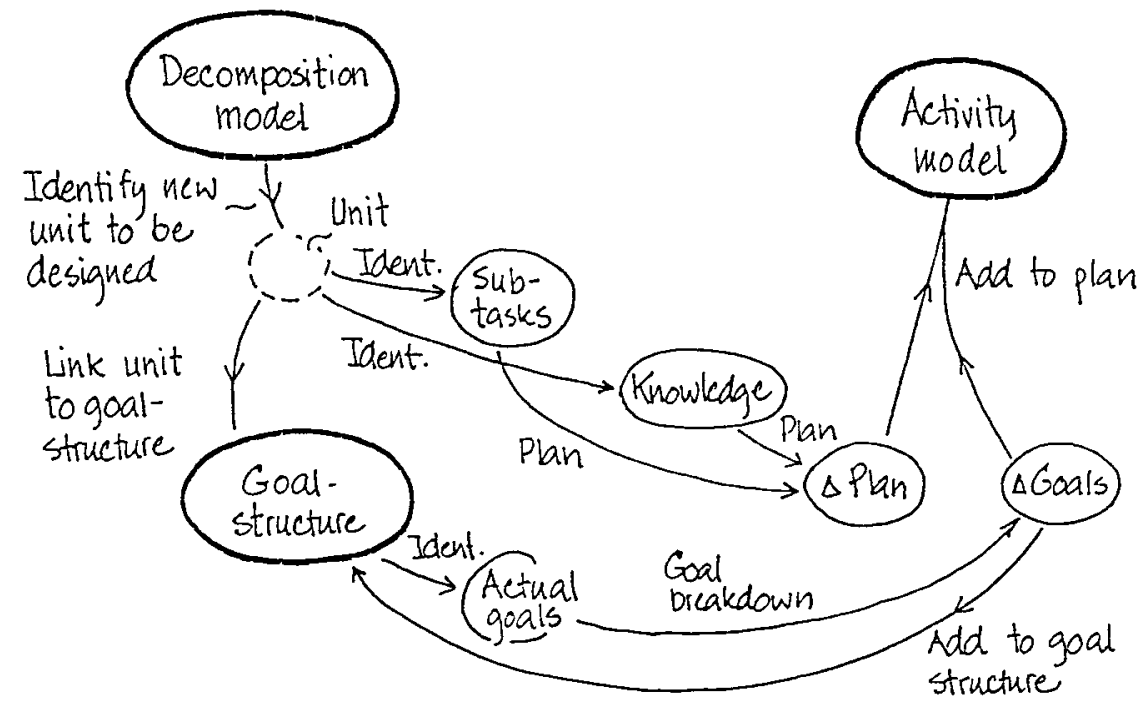

Figure 4 Example of analysis of dynamic changes in the frame network. Here the frames 'decomposition model', 'goal structure' and 'activity model' are related, due to an identification of a new unit in the decomposition structure. 
A pragmatic/empirical approach would be to select a company, point out an actual project and to let the participants identify their co-ordination problems and the dynamic change-patterns in a prototype set-up of a computer based Design Coordination Support System (DCSS). This prototype could, as the first simple solution, be a white-board model of the frames and yellow "post-it" slips carrying the dynamic changes.

\section{Discussion}

Appropriate and fully developed mechanisms and frames for Design Co-ordination do not exist, either paper-based, in manual design today, or as computer-based design support systems. Thus, a critical condition for Design Co-ordination feasibility is that we are able to create frames which in themselves are of advantage to the execution and management of design.

The set of frames shown in Figure 1 reflect the design activity by the following frames: "Model of decomposition" and "Systems matrix model", not by automatic techniques, but as notes or indications from the design agents: Where are we? What are we working on? What results are obtained?

The set of frames is a neutral, generic, structure and gives only benefits, if it is utilised. It is well known from literature that a structured procedure and good use of earlier solutions both create high efficiency and quality results. Properly managed, the DCF could influence design in a very positive way, but will also change the nature of design, by prescriptive patterns, by external control of intermediate results, by monitoring progress against goals and tasks etc.

Some general principles concerning designing in a computer based DC Support System (DCSS) has been identified as:

- Any type of design support shall be accessible at any time (functional, conceptual or concrete). The DCSS should not dictate one design methodology but be flexible for individual types.

- It shall be possible to design the design approach. There are big differences in designers individual approaches: experimental, reuse, trial-and-error, mainly concrete or conceptual focused, with many/few alternatives, with individual graphic stile etc.

- The DCSS shall be integrated with existing and new information structures of the company.

- The DCSS needs to model the product structure (to be based on a product model) in order to aid the design process and Design Co-ordination. 
From the paper it can be seen that Design Co-ordination is a complex task, based on many different factors. Some of the task is related to each of the frames in order to make them function as stand alone elements, while some is related to the co-ordination of the framework data.

Some principles concerning the utilisation of the DCF through a support system has crystallised during our discussions:

- Accessibility has to be able to be managed. The system should support different agents with different roles and responsibilities in the design activity

- The system should model relations between frames and, by allowing different ways of reasoning about their consistency, support their management.

- The system should allow reuse of any models or data of Design Coordination.

- The system should allow interactive analysis of the interaction, evolution and knowledge/activity-use to allow "design learning" and design research.

- It would be attractive, if the system allowed animation of the design activity, for example, for training purposes based on analysis of the design activity. Similarly, it would be attractive if the system allowed simulation and game playing.

- The system's task is to integrate, model and manage (support management) of the interaction between the DC frames.

\section{Conclusion}

This paper has presented a set of "frames" which are considered to be key elements in the effective co-ordination of the design product development process. The framework acts as a foundation upon which to focus our research efforts into enhancing the product development process. It is based upon the author's research experience and discussions with industrialists. Consequently, it requires more rigorous validation on a theoretical and practical basis. Having said this, it highlights that there is still considerable work and research effort required before the framework can adequately reflect and support Design Co-ordination.

\section{Acknowledgements}


The authors express their thanks to Dr S M Duffy for her work and contribution in Design Complexities and Team Engineering and wish to express their gratitude to the individuals and companies, who have joined the discussions and in this way have inspired and focused the work:

- M.L. Boerstra, Stork Demtec, NL

- P. Carr, Digital Scotland Ltd., UK

- Lars Hein, Institute of Product Development, DTU, Denmark

- D. Rimmer, Pilkington Optronics Ltd., UK

- Brian Sinclair, Mentec International, Ireland

- A. Travers, Scottish Design, UK

- Michael Vaag, Danfoss Ltd. Denmark

- Gert Yde, Bang \& Olufsen A/S, Denmark

\section{References}

1. Design for Competitive Advantage - Making the most of design. in International Conference on Design for Competitive Advantage. 1994. Coventry UK: Institute of Mechanical Engineers.

2. Gregory, S.A. Business, engineering design and management,. in Proceedings of the International Conference on Engineering Design Hamburgh 26-28 August 1985. 1985. Heurista Zurich.

3. Chalmet, L.J. Increasing your competitive advantage through CIM,. in Proceedings of the Third CIM Europe Conference Knutsford UK 19-21 May 1987. 1987. IFS(Publications) Ltd UK/Springer-Verlag Berlin.

4. Deasley, P.J. and S.J. Williams. Competive products through innovative control,. in Proceedings of the International Conference on Engineering Design Harrogate UK 22-25 August 1989. 1989. Mechanical Engineering Publications Ltd.

5. Stenberg, H. Design flexibility - a competive factor?,. in Proceedings of the International Conference on Engineering Design Harrogate UK August 22-25 1989. 1989. Mechanical Engineering Publications Ltd.

6. Pennel, J.P., et al. Concurrent Engineering: an overview for Autotestcon,. in IEEE Internation Automatic Testing Conference The Systems Readiness Technology Conference Philadelphia PA USA 25-28 September 1989. 1989. (it IEEE Piscataway NJ USA.

7. Foreman, J.W. Gaining competitive advantage by using simultaneous engineering to integrate your engineering, design and manufacturing resources,. in Conference Proceedings of Autofact Detroit Michigan 30 October-2 November 1989. 1989.

8. Sprague, R.A., K.J. Singh, and R.T. Wood, Concurrent engineering in product development,. IEEE Design and Test of Computers, 1991. 8(1): p. 6-13.

9. Jackson, S. and M. Romeri, World class product development,. Manufacturing Breakthrough: Managing the Design and Development Process, 1992. 1(4): p. 233238. 
10. IT R\&D Programme Computer-integrated manufacturing and engineering: Summaries of Esprit projects I and II - December 1993, ed. S. Rogers and M. Vereczkei. 1994, European Commision Directorate-General XIII Telecommunications Information Market and Exploitation of Research: Luxembourg.

11. Gilmore, D., Keeping PACE with the market,. World Class Design to Manufacture, 1994. 1(1): p. 12-16.

12. IFIP WG5.7 Working Conference on Managing Concurrent Manufacturing to Improve Industrial Performance, Seattle, Washington, USA, 11-15 September 1995, .

13. Manufacturing Breakthrough: Managing Product Development, , Information for Success (IFS) Ltd Publishers Bedford UK.

14. World Class Design to Manufacture, , MBC University Press Ltd Bradford UK.

15. Roboam, M., GRAI-IDEF-Merise (GIM): Integrated methodology to analyse and design manufacturing systems,. Journal of Computer Integrated Manufacturing Systems, 1989. 2(2): p. 82-89.

16. Kosanke, K., The European approach for an Open System Architecture for CIM (CIM-OSA) - ESPRIT project 528 AMICE,. Computing \& Control Engineering Journal, 1991: p. 103-108.

17. Vasilash, G.S., Simultaneous engineering: management's new competitiveness tool,. Production, 1987. 99(7): p. 36-41.

18. Coplin, J.F. Engineering design - a powerful influence on the business success of manufacturing industry, in Proceedings of the International Conference on Engineering Design Harrogate UK 22-25 August 1989. 1989. Mechanical Engineering Publications Ltd.

19. Improving Engineering Design: Designing for competitive advantage,. 1991, Washington DC USA: National Research Council, National Academy Press.

20. Deisenroth, M.P., J.P. Terpenny, and O.K. Eyada. Design for competitiveness: case studies developed in concurrent engineering and design for manufacturability,. in The Winter Annual Meeting of the American Society of Mechanical Engineers Anaheim CA USA 8-13 November 1992. 1992. ASME New York NY USA.

21. Jaikumar, R., Project Portfolios, , Fourth International Forum on Technology Management Berlin Germany 18-20 October 1993.

22. Finger, S. and J.R. Dixon, A review of research in mechanical engineering design. part 1: descriptive, prescriptive and computer based models of design processes,. Research in Engineering Design, 1989. 1: p. 51-71.

23. Duffy, S.M. The Design Complexity Map and the Design Coordination Framework, in Proceedings of the tenth Integrated Production Systems Research Seminar. 1995. Fuglsoe, Denmark.

24. Olesen, J., Concurrent development in manufacturing based on dispositional mechanisms, in Institute for Engineering Design. 1992, Technical University of Denmark: 2800 Lyngby. 
25. Polito, J., A. Jones, and H. Grant, Enterprise integration: A tool's perspective,, in Information and collaboration models of integration, S.Y. Nof, Editor. 1994, Kluwer Academic Publishers: Dordrecht The Netherlands. p. 149-167.

26. Andreasen, M.M., et al., Design for Assembly,. 1987: IPS Publications/Springer-Verlag London UK.

27. Tichem, M. Design for manufacturing and assembly: a closed loop approach,. in Proceedings of the Ninth International Conference on Engineering Design The Hague 17-19 August 1993. 1993. Heurista Switzerland.

28. Institute for Product, D., Design for Manufacture: A guide for improving the manufacturability of industrial products, 1994.

29. Miles, B.L. and K.G. Swift, Working together,. Manufacturing Breakthrough, 1992. 1(2).

30. Andreasen, M.M. and L. Hein, Integrated Product Development,. 1987: IFS (Publications) Ltd and Springer-Verlag London UK.

31. Ashley, S., DARPA initiative in concurrent engineering,. Mechanical Engineering, 1992: p. 54-57.

32. Sriram, D., R. Logcher, and S. Fukuda, eds. Proceedings of the MIT-JSME

Workshop on Cooperative Product Development,. . 1989: Dept. of Civil Engineering, Massachusetts Institute of Technology, Cambridge, MA, USA.

33. Computer-Aided Cooperative Product Development,, , D. Sriram and R. Logcher, Editors. 1991, Springer-Verlag: New York USA.

34. Klein, M. and S.C.Y. Lu. Insights into cooperative group design: experience with the LAN design system, in Proceedings of the Sixth International Conference on Applications of Artificial Intelligence in Engineering. 1991. University of Oxford UK.

35. Sriram, D., et al., DICE: An object-oriented programming environment for cooperative engineering design,, in Artificial Intelligence in Engineering Design: Knowledge acquisition commerical systems and integrated environments, C. Tong and D. Sriram, Editors. 1992, Academic Press Inc.: San Diego CA USA. p. 303366.

36. Visser, W. Collective design: a cognitive analysis of cooperation in practice,. in Proceedings of the Ninth International Conference on Engineering Design The Hague 17-19 August 1993. 1993. Heurista Switzerland.

37. Anupam, V. and C.L. Bajaj, Shastra: multimedia collaborative design environment,. IEEE Multimedia, 1994: p. 39-49.

38. McGuire, J.G., et al., SHADE: Technology for knowledge-based collaborative engineering,. Journal of Concurrent Engineering: Applications and Research (CERC), 1993. 1(3): p. 137-146.

39. Toye, G., et al., SHARE: A methodology and environment for collaborative product development, in Proceedings of the 2nd Workshop on Enabling Technologies: Infrastructure for Collaborative Enterprises. 1993, IEEE Computer Press. p. 22-47.

40. Kusiak, A. and K. Park, Concurrent Engineering: decomposition and scheduling of design activities,. International Journal of Production Research, 1990. 28(10): p. 1883-1900. 
41. Eppinger, S.D., Model-based approaches to managing concurrent engineering,. Journal of Engineering Design, 1991. 2(4): p. 283-290.

42. Kusiak, A. and J. Wang, Decomposition of the design process,. Journal of Mechanical Design, 1993. 115: p. 687-695.

43. Kusiak, A. and U. Belhe, Scheduling design activities, in Information and collaboration models of integration, S.Y. Nof, Editor. 1994, Kluwer Academic Publishers: Dordrecht The Netherlands. p. 43-60.

44. Pourbabai, B. and M. Pecht, Management of design activities in a concurrent engineering environment,. International Journal of Production Research, 1994. 32(4): p. 821-832.

45. Eppinger, S.D., et al., A model-based method for organising tasks in product development, Research in Engineering Design, 1994. 6(1): p. 1-13.

46. CIMDEV Working Group 7401,, in IT R\&D Programme Basic Research: Summaries of Esprit projects working groups and networks of excellence December 1993, S. Rogers and M. Vereczkei, Editors. 1994, European Commision Directorate-General XIII Telecommunications Information Market and Exploitation of Research: Luxembourg. p. 404-407.

47. MacCallum, K.J., Requirements for intelligent support of concurrent engineering,, in Artificial Intelligent in Design (AID'92) Workshop. 1992: Carnegie-Mellon University, Pittsburgh, USA.

48. Duffy, A.H.B., et al., Design coordination for concurrent engineering,. International Journal of Engineering Design, 1993. 4(4): p. 251-265.

49. Roozenburg, N.F.M. and J. Eekels, Product Design: Fundamentals and Methods. Product Development - Planning, Designing, Engineering, ed. N. Cross and N. Roozenburg. 1995: John Wiley \& Sons Ltd., Chichester Po19 1UD, United Kingdom.

50. Pahl, G. and W. Beitz, Engineering Design: A systematic approach,. English, 2nd ed, ed. K. Wallace. 1996, London: Springer.

51. Hollins, W.J. and S. Pugh, Successful Product Design - What to do and When. 1990, London: Butterworth.

52. Edwards, S. and P. Lewis, The Product Introdcution Process. 1991, Birmingham: Lucas Engineering \& Systems Ltd.

53. Reinders, H., From abstract idea until production,. 1989, CTB Report 23/89EN, Centre for Manufacturing Technology, Philips Bedrijven BV: Eindhoven.

54. Minne, H.P. and M.L. Boerstra, Computer Aided Design for Manufacture - a tool to be used at a designers workbench, in Proc. CIRP Conference. 1990: Entschede.

55. Pugh, S., Total Design: Integrated methods for successful product engineering,. 1990, Wokingham England UK: Addison-Wesley Publishing Company.

56. Hananel, D., H. Hjort, and D. Lucas, Customer Focused Product Planning \& Implementation, . 1991, Innovata Inc.: Cincinnati, Ohio, USA.

57. Sheldon, D.F., Designing for whole life costs at the concept stage. Journal of Engineering Design, 1990. 1(2). 
58. Svendsen, K.H., Optimisation of composite mechanical systems, in Institute for Engineering Design. 1994, Technical University of Denmark: 2800 Lyngby.

59. Azarm, S. and W.C. Li, A two-lvel decomposition method for design optimisation. Engineering Optimisation, 1988. 13.

60. Sobieszczanski-Sobieski, J., Interdisciplinary and MultiLevel Optimum Design. Computer aided optimal design - structural and mechanical systems. 1987: Springer-Verlag.

61. Duffy, A.H.B., A. Persidis, and K.J. MacCallum, NODES: a Numerical and Object based modelling system for conceptual engineering DESign. KnowledgeBased Systems, 1996. 9: p. 183-206.

62. Corbett, J., ed. Design for Manufacture. . 1991, Addison-Wesley: New York. 63. Perks, R., D. Sheldon, and S. Bush. Whole life cost. in WDK Workshop Design for $X$. 1993. Institute for Engineering Design, Technical University of Denmark, 2800 Lyngby, DK.

64. Syan, C.S. and U. Menon, eds. Concurrent Engineering - Concepts, Implementation and Practice. . 1994, Chapman \& Hall Ltd.: London.

65. Clausing, D. and S. Pugh. Enhanced Quality Function Deployment. in Int. Conf. on Design and Productivity. 1991. Honolulu, Hawai, USA.

66. Ropohl, G., Flexible Fertingungs Systeme, . 1971, Otto Krausskopf-Verlag $\mathrm{GmbH}$ : Mainz. 